\title{
A male with a de novo translocation involving loss of 15q11q13 material and Prader-Willi syndrome
}

\author{
S Vickers, M Dahlitz, C Hardy, M Kilpatrick, T Webb
}

\begin{abstract}
A male proband is described who carries a de novo translocation between chromosomes $Y$ and 15 associated with PraderWilli syndrome. In situ hybridisation and molecular studies were used to show loss of the paternally derived $15 q 11$ q13 region in the translocated chromosome. Lack of further symptoms indicate that this region was lost with no apparent deletion of the $Y$ chromosome.
\end{abstract}

( $\mathcal{F}$ Med Genet 1994;31:478-481)

Prader-Willi syndrome (PWS) is characterised by hypotonia and feeding difficulties in the neonatal period, with the childhood development of hyperphagia leading to obesity, developmental delay, hypogonadism, short stature, and small hands and feet. ${ }^{1}$ Approximately 70 to $75 \%$ of probands have a microscopically or submicroscopically detectable de novo deletion of $15 \mathrm{q} 11 \mathrm{q} 13$ in the paternally derived homologue of chromosome $15 .^{2}$ The majority of the remaining 25 to $30 \%$ of probands have been shown to have maternal uniparental disomy $^{3}$ and it has been suggested that all typical PWS probands can be accounted for by one of these two mechanisms. ${ }^{4}$ Both mechanisms involve the loss of the paternal contribution in $15 \mathrm{q} 11 \mathrm{q} 13$ and this loss is not compensated for by the presence of two maternal copies of this region.

Apart from the de novo deletion in $15 q 11$ q13, approximately $5 \%$ of PWS has

Clinical Genetics Unit, Birmingham Maternity Hospital, Edgbaston, Birmingham B15 2TG, UK

S Vickers

C Hardy

M Kilpatrick

$T$ Webb

Institute of Psychiatry, De Crespigny Park, Denmark Hill, London SE5 8AF, UK M Dahlitz

Correspondence to Dr Vickers

Received 25 November 1993 Revised version accepted for publication 11 January 1994
Kousseff et $a l^{T}$ reported a boy with PWS associated with a complex mosaic karyotype given as: $45, \mathrm{X}, \mathrm{t}(\mathrm{Y} ; 15)$ with partial deletion 15 (15pter-15q12); 46,X,t(Y;15), dic(15)(15pter$15 \mathrm{q} 12:: 15 \mathrm{q} 12-15 \mathrm{pter})$ and $47, \mathrm{X}, \mathrm{t}(\mathrm{Y} ; 15)$, $\operatorname{dic}(15), \operatorname{dic}(15)$.

In the course of a clinical, cytogenetic, and molecular study of Prader-Willi syndrome, a male proband was found to carry a Y;15 translocation. He was further investigated to try to determine the exact breakpoints involved in the translocation and whether or not it was accompanied by loss of chromatin from the Prader-Willi chromosomal region (PWSCR) of chromosome 15.

\section{Case report}

The proband is now 25 years old, is $178 \mathrm{~cm}$ tall, and weighs $68 \mathrm{~kg}$. He was born when both his parents were aged 26 . He has a brother who had a specific writing difficulty with word reversal in childhood but is otherwise normal. His father is West Indian-Spanish-Chinese with seven healthy sibs. His mother is AngloIrish with six healthy sibs. There is no known family history of Prader-Willi syndrome or learning disability.

The proband's mother had no known miscarriages but had a threatened abortion when four months pregnant with the proband. As is characteristic in the Prader-Willi syndrome, there were no fetal movements during the pregnancy and the proband was floppy at birth with a weak sucking reflex. He was noted to have undescended testes and a small penis. He was late to reach his developmental milestones and was unable to talk until he was 4 years or walk until 5 years. He later attended both normal schools and schools for the handicapped. He was doubly incontinent until the age of 8 . He gained weight with alarming speed; his birth weight was $2722 \mathrm{~g}$ but at 9 months he weighed $11.3 \mathrm{~kg}$. His mother has restricted his food since early childhood to prevent severe obesity. His family report that he has many behavioural characteristics of the Prader-Willi syndrome including hoarding, particularly of food, stealing, and being over assertive. In addition to signs and symptoms typical of the Prader-Willi syndrome, the proband had severe bruising secondary to broken superficial blood vessels at birth and convergent upward strabismus. A diagnosis of "autism" was considered until the age of 19 years. 
His four wisdom teeth required extraction but his dentition was otherwise normal. Although he developed pubic hair, facial hair only grew on the upper lip and his voice has not deepened. He continues to live with his parents and requires continuous supervision. Consideration of his age, family structure, and the presence of a Y;15 translocation suggested that he could be the same patient who had been investigated at Guy's Hospital in 1976 at the age of 8 years ${ }^{5}$ (C Berry, personal communication). A detailed clinical examination of the proband at that time ${ }^{5}$ suggested typical Prader-Willi syndrome although his weight was being controlled by diet.

\section{CYTOGENETIC STUDIES}

Cytogenetic studies were carried out on the proband, his parents, and his brother. Chromosomes were elongated to the 850 band level and slides stained with GTG, Ag/NOR, CBG, and distamycin/DAPI.

Both parents and the unaffected brother had normal karyotypes but the proband was found to carry a translocation. His karyotype was apparently $45, \mathrm{X},-\mathrm{Y},-15,+\operatorname{der}(\mathrm{Y}) \mathrm{t}(\mathrm{Y} ; 15)(\mathrm{p} 11.3$; q13) (fig 1). Silver staining showed that the translocated chromosome did not carry a NOR (nucleolar organiser region) and that his normal 15 homologue was maternally derived. CBG staining confirmed that the short arm of the translocated chromosome was heterochromatic and suggested that the centromere was $\mathrm{Y}$ and not 15 derived. Distamycin/DAPI staining confirmed the absence of a chromosome 15 short arm in the derivative chromosome. No cell line is available from this patient.

\section{FLUORESCENCE IN SITU HYBRIDISATION (FISH)}

Chromosome spreads were hybridised with $Y$ whole chromosome paint, a biotinylated $\mathrm{Y}$ centromeric probe ( $\mathrm{pDP} 97$ ), 15 whole chromosome paint, and two probes specific for $15 \mathrm{q} 11 \mathrm{q} 13$ (Oncor probes A and B). One of these latter probes hybridises to the PWS critical region and the other to the more distal ${ }^{8}$ Angelman syndrome (AS) region. Hybridisations were carried out according to the manufacturer's instructions.

Fluorescence in situ hybridisation (FISH) with whole $\mathrm{Y}$ chromosome paint confirmed the CBG banding and showed that the translocated chromosome contained apparently all of the paternal $\mathrm{Y}$ including the short arms. The short arm of the abnormal chromosome and the region immediately proximal to the centromere on the long arm was $\mathrm{Y}$ chromosome derived (fig 2, above). Use of the $\mathrm{Y}$ centromere specific probe DYZ3 confirmed that the centromere was $\mathrm{Y}$ and not 15 derived (fig 3). Painting with chromosome 15 paint showed that the pericentromeric region of the abnormal chromosome including the proximal $\mathrm{q}$ arm was not derived from chromosome 15 and finally only one fluorescent signal was observed when two probes specific for the PWS and AS regions respectively were used.
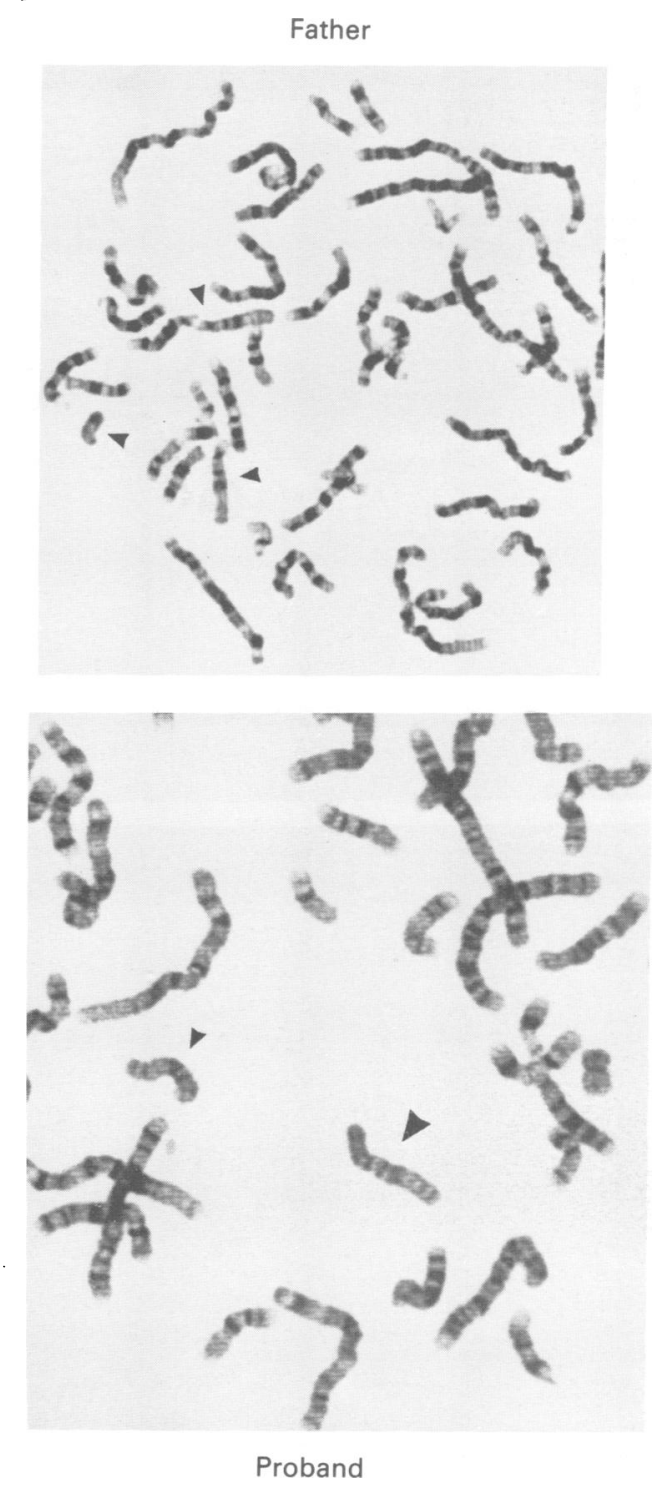

Figure $1 G$ banded mitotic figures from the proband and his father. Chromosomes 15 are arrowed as is the paternal $Y$ chromosome. The derivative chromosome present in the proband has a large arrow.

Neither of these 15q11q13 specific probes hybridised to the translocated chromosome; both localised only to the normal chromosome 15 homologue.

\section{MOLECULAR STUDIES}

DNA was isolated from the proband, both of his parents, and his unaffected brother using standard methodology. PCR based analysis for three microsatellite markers at the D15S11, GABRB $3,{ }^{9}$ and GABRA $5^{10}$ loci was performed. For each microsatellite, approximately $100 \mathrm{ng}$ of genomic DNA was amplified using one radiolabelled and one unlabelled primer, and 2 to $3 \mu \mathrm{l}$ of the amplified product was resolved by electrophoresis on a $6 \%$ denaturing polyacrylamide gel. Detection of radiolabelled PCR products was by autoradiography at $-70^{\circ} \mathrm{C}$.

Of the three microsatellites tested only the GABRA5 locus was fully informative in the family. The proband was found to have inherited only a maternally derived copy of this gene; the paternal allele had become deleted (fig 4). 

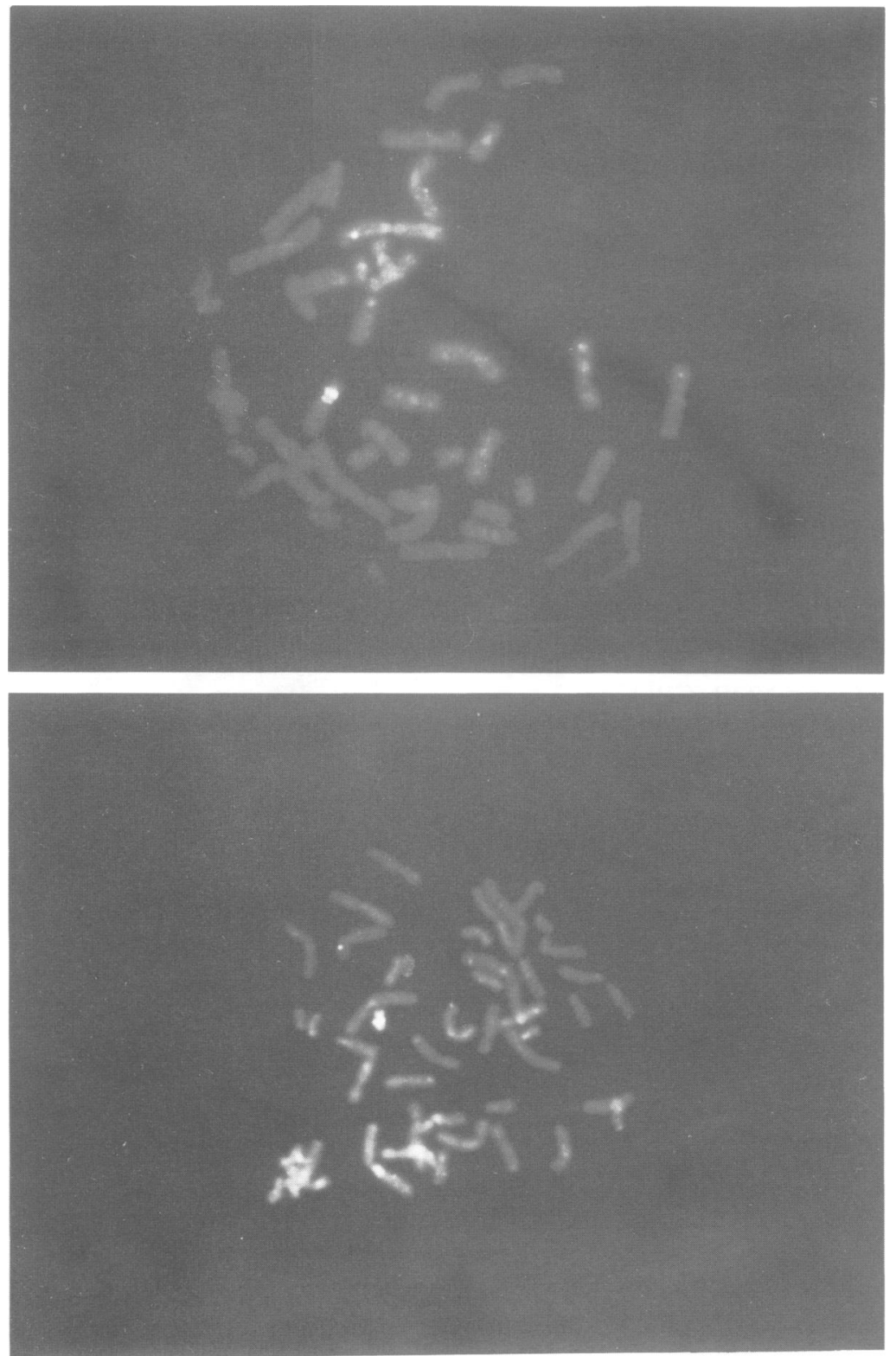

Figure 2 Mitotic figures from the proband (above) and his father (below) after in situ hybridisation with whole $Y$ chromosome paint. The derivative chromosome has $Y$ chromatin both above and below the centromere. Comparison with the paternal $Y$ chromosome suggests that very little $Y$ material has been deleted.

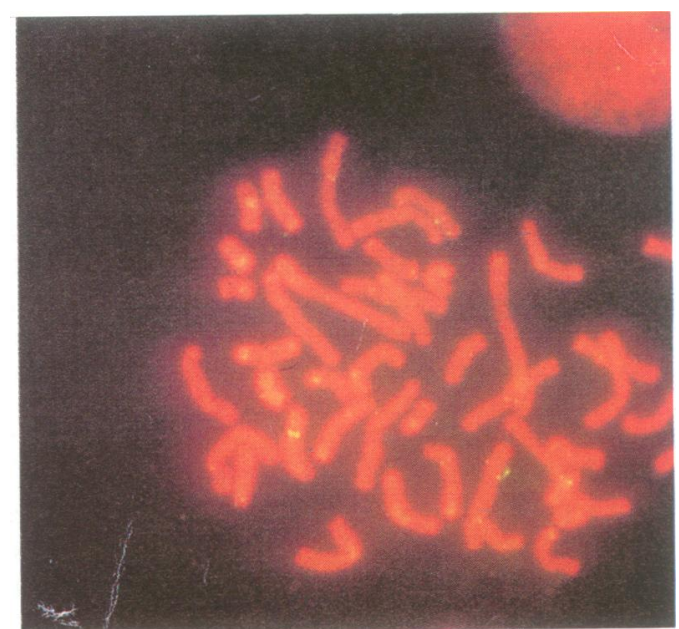

Figure 3 Fluoresence in situ hybridisation (FISH) of a $Y$ centromere specific probe (DYZ3) to the derivative chromosome showing that the centromere is $Y$ derived.

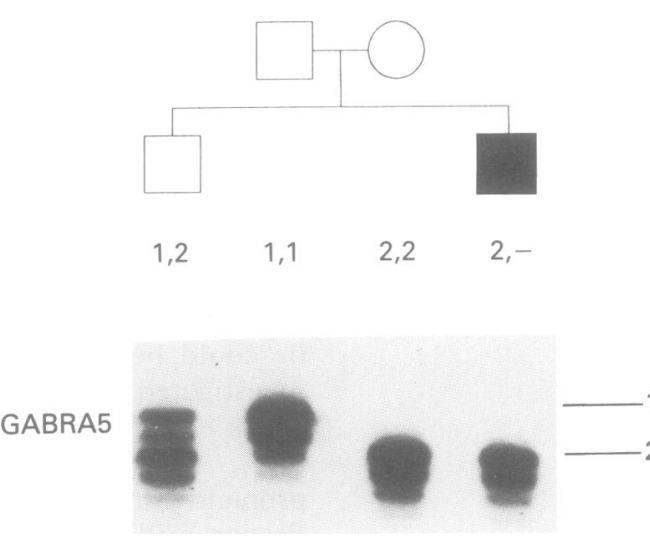

Figure 4 Genotypings of family members for the microsatellite marker for the GABRAS locus.

Biparental inheritance of chromosome 15 homologues in the proband was shown by hybridisation of the telomeric VNTR marker pMS620 (D15S86) to Southern blotted, restriction enzyme digested DNA samples.

\section{Discussion}

A male proband is described who carries a de novo translocation between chromosomes $\mathrm{Y}$ and 15 associated with Prader-Willi syndrome. Although he has a small penis and hypogonadism it is probable that these are part of the spectrum of the Prader-Willi syndrome and are not the result of the loss of $\mathrm{Y}$ chromosome material.

The proband therefore has typical PraderWilli syndrome owing to a deletion in the paternal $15 \mathrm{q} 11 \mathrm{q} 13$ region which arose during a translocation between one paternal 15 and his $\mathrm{Y}$ chromosome. The other chromosome 15 homologue present in the proband was shown both by cytogenetic and molecular studies to be maternally derived.

The translocation between chromosomes $\mathrm{Y}$ and 15 in this subject differs from those observed by Kousseff $e t a l$ and Qumsiyeh $e t$ $a l .{ }^{6}$ In these cases the breakpoints in both the 15 and the $\mathrm{Y}$ are located in the $\mathrm{q}$ arm giving a tandem configuration in the derivative chromosome. In the case reported by Qumsiyeh et $a l^{6}$ in situ hybridisation studies suggested a breakpoint in the $\mathrm{Y}$ chromosome at $\mathrm{q} 12$ and a breakpoint in the chromosome 15 at q11.2; hence the proband was deleted for 15pterq11.2 (pat) and for Yq12-Yqter.

Similarly the complex arrangement found by Kousseff et $a l$ resulted in a derivative chromosome with breakpoints at $15 \mathrm{q} 12$ and Yq12. Despite the presence of additional dic(15) markers in a percentage of cells, the greater majority ( $74 \%$ ) had only this translocation present without the additional markers. Thus there is a marked similarity in the derivative chromosome between these two cases. In neither case was the father of the proband available for study.

In the case reported here, the breakpoint in the $\mathrm{Y}$ chromosome is at $\mathrm{Yp} 11.3$ with very 


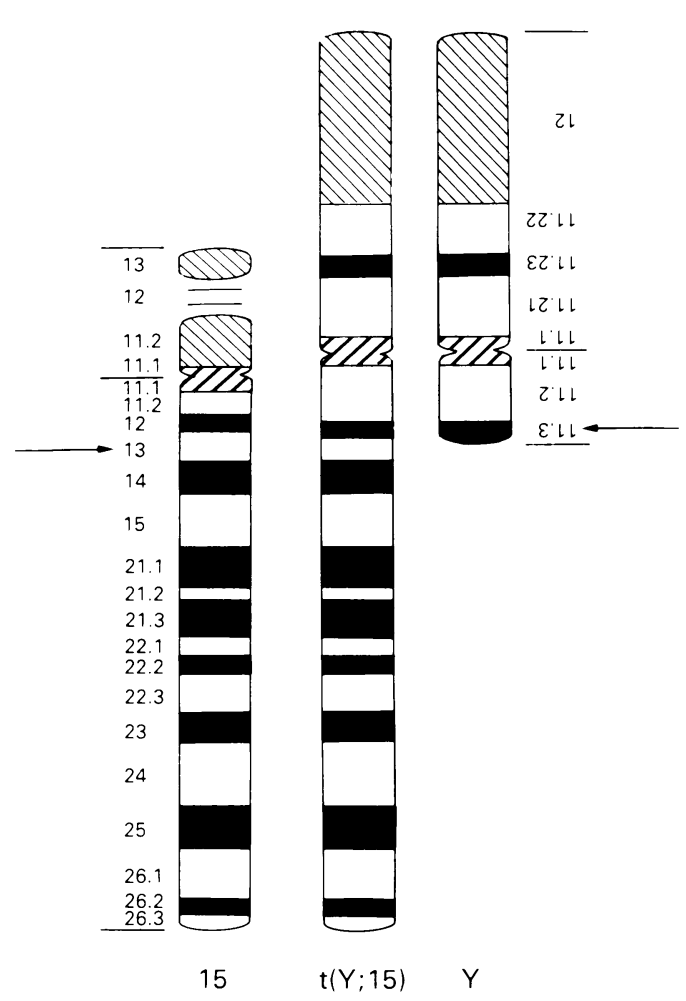

Figure 5 Diagrammatic representation of chromosomes 15 and $Y$ with the translocation chromosome. The breakpoints are arrowed.

little, if any, loss of $\mathrm{Y}$ material from the short arm and none at all from the long arm (fig 5).

We believe that this is the first time that fluorescence in situ hybridisation using probes from the $15 \mathrm{q} 11 \mathrm{q} 13$ region has shown the pres- ence of a deletion in a PWS proband with a translocation which involves the pericentromeric region of chromosome 15 . Although the translocation is de novo, if the proband's father is a gonadal mosaic, then the recurrence risk for this family may be very high.

We would like to thank Dr Caroline Berry for confirming that the proband had been previously ascertained and for sending us a detailed clinical assessment of him at that time. Carol Hardy is supported by the Mental Health Foundation.

1 Butler MG, Meaney FJ, Palmer CG. Clinical and cytogenetic survey of 39 individuals with Prader-Labhart-Willi etic survey of 39 individuals with Prader-Lab

2 Ledbetter DH, Riccardi VM, Airhart SD, Strobel RJ Keenan SB, Crawford JD. Deletions of chromosome 15 as a cause of the Prader-Willi syndrome. N Engl f. Hed 1981;304:325-9.

3 Nicholls RD, Knoll JHM, Butler MG, Karam S, Lalande M. Genetic imprinting suggested by maternal heterodisomy in non-deletion Prader-Willi syndrome. Nutur 1989;342:281-5.

4 Robinson WP, Bottani A, Yagang X, it al. Molecular, cytogenetic and clinical investigations of Prader-W'illi syndrome ane tm f Hum Gene 1991:49:1219-34.

5 Berry AC, Whittingham AJ, Neville BGR. Chromosome 15 in floppy infants. Arch Dis ('hild 1981;56:882-5.

6 Qumsiyeh MB, Dalton JD, Gordon PL, Wilroy RS, Tharapel AT. Deletion of chromosome 15pter-411.2 due to $\mathrm{t}(\mathrm{Y}: 15$ in a boy with Prader-W'illi syndrome. Am 7 . Med Genet 1992;42:109-11

7 Kousseff BG, Diamond T, Essig Y, Miller K, Tedesco T. Unique mosaicism in Prader-Labhart-Willi sundromecontiguous gene or aneuploidy sundrome? $\mathrm{Am}$. $\mathrm{Hed}$ Genet 1987;28:803-11

8 Kuwano A, Mutirangura A. Dittrich B, it al. Molecular dissection of the Prader-Willi Angelman syndrome redissection of the Prader-Will Angelman syndrome re-
gion 15q11-13 by YAC cloning and FISH analysis. Hum gion 15q11-13 by YAC clo

9 Wagstaff J, Knoll JHM, Fleming J, et al. Localization of the gene encoding the $\mathrm{GABA}_{+}$receptor $\mathrm{B} 3$ subunit to the Angelman Prader-Willi region of human chromosome 15. Am f Hum Ginet 1991;49:330-7.

10 Knoll JHM, Sinnett D, Wagstaff J, et al. FISH ordering of reference markers and of the gene for the 5 subunit of the $x$-aminobutyric acid receptor GABRA5 within the Angelman and Prader-Willi syndrome chromosomal regions. Hum .11ol (Gonet 1993;2:183-9. 